\title{
RANCANG BANGUN APLIKASI ANTI MALING PADA KENDARAAN BERMOTOR RODA DUA MENGGUNAKAN GPS (Global Positioning System) BERBASIS INTERNET
}

\author{
Raiza1 , I Wayan Sudarsana², Resnawati ${ }^{3}$ \\ 123Program Studi Matematika Jurusan Matematika \\ Fakultas Matematika dan IImu Pengetahuan Alam Universitas Tadulako \\ Jalan Soekarno-Hatta Km. 09 Tondo, Palu 94118, Indonesia. \\ 11raizadwidiadiningrum@gmail.com, 2sudarsanaiwayan@yahoo.co.id, 3r35n4w4t1@yahoo.com
}

\begin{abstract}
Now days there are a lot of different security systems for vehicle such as alarm, magnetic lock, GPS, and etc. However this security system is far from perfection because when the system is hacked, the vehicle can be easily be operated and stolen. The rapid technological advances have been able to ease vehicle's owner to track location of the vehicle. The GPS use together with SMS technology can help the owner to observe and control the vehicle. The purpose of this research is to create vehicle anti-theft application using GPS in smartphone Android and GPS in the vehilce's module based on internet that is called GP search AMK. The methods used in this application are Djikstra Alogaritma and google maps API to find out the shortest path and navigation guide. The results of this research are application and a complex security system. This application consisted of buttons and icons that can make the owner easier in accessing, observing, and controlling his vehicle. The buttons and icons are functioned to choose which vehicle to be observed, to track the nearest police station and position of the vehicle, to track the shortest path between owner and and vehicle, to arrange time for sending vehicle's coordinate to server, to stop the sending of coordinates, to shut down the machine, to show the average of speed of the vehicle, to show latest gasoline, to show navigation of signpost and to show the distance needed to be taken from police station to the vehicle.
\end{abstract}

Keywords : Djikstra Algorithms, GPSearch AMK Applicaton, GPS, Internet, SMS.

\section{ABSTRAK}

Kemajuan teknologi yang sangat cepat saat ini memudahkan bagi para pemilik kendaraan bermotor untuk melacak keberadaan kendaraannya. Penggunaan GPS yang dipadukan dengan teknologi SMS akan memberikan kemudahan bagi pemilik kendaraan untuk memantau dan mengontrol kendaraannya. Penelitian ini bertujuan untuk membuat aplikasi anti maling kendaraan bermotor menggunakan GPS pada smartphone Android dan GPS pada modul kendaraan bermotor yang berbasis internet dan disebut GPSearch AMK. Metode yang digunakan pada aplikasi ini adalah Algoritma Dijkstra dan Google maps API untuk mencari jalur terpendek dan navigasi pemandu jalan. Hasil penelitian ini berupa aplikasi dan sistem pengamananlebih kompleks, dimana di dalam aplikasi ini terdapat tombol-tombol dan tampilan ikon yang akan memudahkan pemilik kendaraan untuk 
mengakses, memantau, atau mengontrol kendaraannya. Tombol-tombol dan tampilan ikon tersebut berfungsi untuk memilih kendaraan yang akan dipantau, mengecek kantor polisi terdekat dengan posisi kendaraan bermotor, mengecek jalur terpendek antara User ke kendaraan bermotor, mengatur waktu pengiriman koordinat kendaraan ke server, menghentikan pengiriman koordinat koordinat, mematikan mesin, menunjukkan kecepatan rata-rata kendaraan bermotor, menunjukkan jumlah bensin kendaraan bermotor, menampilkan navigasi penunjuk arah serta menampilkan jarak tempuh yang dibutuhkan.

Kata kunci : Algoritma Dijkstra , Aplikasi GPSearch AMK, GPS, Internet, SMS.

\section{PENDAHULUAN}

Perkembangan teknologi saat ini beriringan dengan meningkatnya jumlah pemilik kendaraan roda dua (motor), maka sistem pengamanan kendaraan menjadi kebutuhan yang cukup utama bagi pemilik kendaraan. Keamanan seperti alarm-alarm kendaraan yang banyak ditawarkan dan digunakan yakni yang menggunakan suara sebagai indikatornya yang merupakan fasilitas standar dari sebuah alarm.

Namun keamanan ini masih jauh dari sempurna karena jika alarm atau pengeras suara tersebut dapat dilumpuhkan maka tidak ada lagi indikator yang digunakan untuk memberikan informasi kepada pemilik mengenai kondisi kendaraannya, kemudian setelah itu mesin kendaraan dapat dengan leluasa dioperasikan dan mudah untuk dicuri (Tjhin, S., dkk, 2014). Ketika kendaraan telah dicuri maka lebih sulit lagi bagi pemilik kendaraan untuk melacak keberadaan kendaraannya, sehingga dibutuhkan suatu aplikasi yang mampumelacak keberadaan kendaraan tersebut. Dengan menggunakan GPS yang dipadukan dengan tekhnologi SMSmaka akan memberikan kemudahan bagi pemilik kendaraan untuk melacak posisi kendaraannya.

Penggunaan GPS pada aplikasi pelacakan kendaraan sangatlah membantu para pengguna kendaraan dalam memantau posisi kendaraannya ketika dicuri, namun GPS hanya berfungsi untuk melacak posisi kendaraan sedangkan untuk memberikan petunjuk jalur terpendek dalam menjangkau tempat kendaraan berada dibutuhkan suatu metode yaitu metode Algoritma Djikstra. Algoritma Djikstra merupakan salah satu metode yang digunakan untuk menemukan jalur terpendek berdasarkan bobot terkecil dari satu titik ke titik lainnya atau dengan kata lain untuk menemukan jalur terpendek antara posisi User ke posisi kendaraan sehigga lebih mudah dan lebih cepat bagi User untuk menjangkau keberadaan kendaraannya (Lubis, 2009).

Andreas Handojo dkk, sebelumnya telah melakukan penelitian mengenai aplikasi pelacakan lokasi rute perjalanan mobil dengan GPS via SMS (Handojo, A. dkk, 2004), namun pada penelitian ini masih belum menampilkan hasil pelacakan posisi secara grafis, posisi pelacakan hanya berupa data text pada SMS. Oleh karena itu, pada penelitian ini akan dikembangkan sebuah aplikasi yang sistem pengamanannya lebih kompleks, dimana di dalam aplikasi ini terdapat terdapat tombol- 
tombol dan tampilan ikon yang lebih memudahkan pemilik kendaraan untuk mengakses, memantau, atau mengontrol kendaraannya.

\section{METODE PENELITIAN}

Penelitian ini dilakukan sesuai prosedur sebagai berikut:

1. Merumuskan masalah.

2. Mengonsep alat dan tampilan aplikasi program.

3. Membuat database.

4. Membuat program dan rangkaian modul.

5. Pembentukan rancang bangun GPSearch AMK.

6. Uji coba penelitian.

7. Menyimpulkan hasil penelitian.

\section{HASIL DAN PEMBAHASAN}

\subsection{Hasil Penelitian}

Hasil dari penelitian ini merupakan sebuah alat dan aplikasi yang dapat digunakan untuk memantau dan mengontrol kendaraan bermotor. Alat dan aplikasi ini dapat menentukan jalur terpendek dari posisi User ke kendaraan bermotor dan posisi kendaraan bermotor ke kantor polisi terdekat yang berada disekitaran Kota Palu. Aplikasi ini juga dapat menampilkan petunjuk navigasi untuk mempermudah User dalam menjangkau kendaraan bermotor, menampilkan tampilan mematikan mesin kendaraan, mengecek bensin, menampilkan kecepatan rata-rata kendaraan, menampilkan pulsa modul/server dan memulai/mengakhiri pengiriman koordinat dari kendaraan ke User.

Pada penelitian ini untuk menentukan jalur terpendek dari posisi User ke kendaraan bermotor dan posisi kendaraan bermotor ke kantor polisi terdekat digunakan metode Algoritma Dijkstra. Berikut contoh perhitungannya pada pencarian jalur terpendek antara User ke kendaraan bermotor.

1. Misalkan User berada pada koordinat $\mathrm{A}$ dan kendaraan bermotor berada di koordinat $\mathrm{H}$, maka dari kedua koordinat diatas diambil gambar pada peta dengan skala yang mencakup kedua koordinat seperti gambar 1 . 


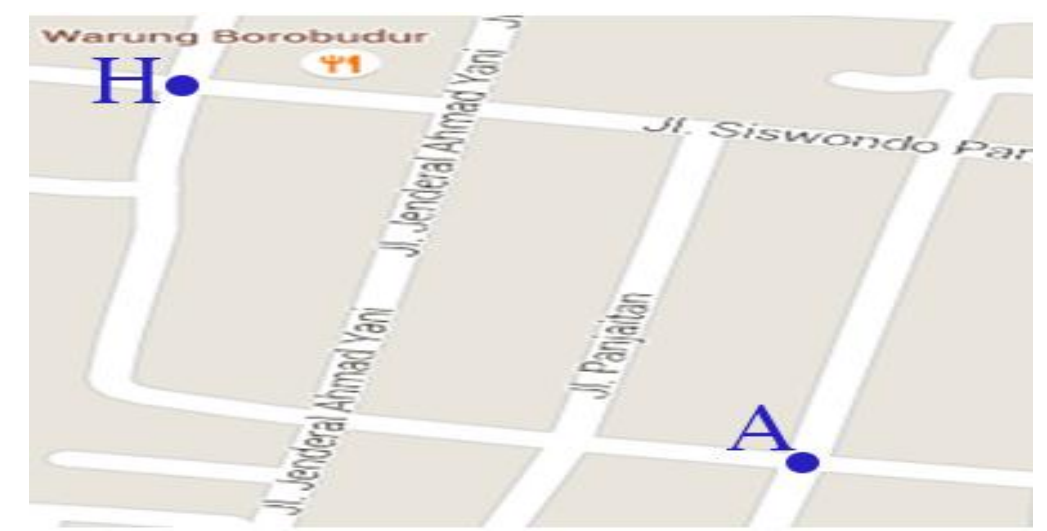

Gambar 1. Peta Google dengan skala yang mencakup kedua koordinat

Dari gambar di atas akan dibentuk graf dari setiap waypoint yang sehingga diperoleh graf waypoint seperti berikut :

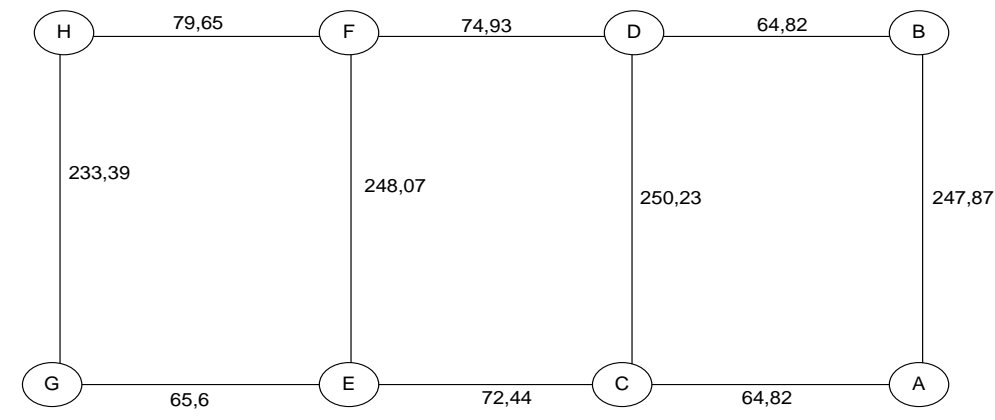

Gambar 2. Graf waypoint

2. Bentuk matriks jarak dari graf waypoint seperti berikut :

Tabel 1. Matriks Jarak

\begin{tabular}{|c|c|c|c|c|c|c|c|c|}
\hline NO & A & B & C & D & E & F & G & H \\
\hline A & 0 & 247.87 & 64.82 & $\infty$ & $\infty$ & $\infty$ & $\infty$ & $\infty$ \\
\hline B & 247.87 & 0 & $\infty$ & 64.82 & $\infty$ & $\infty$ & $\infty$ & $\infty$ \\
\hline C & 64.82 & $\infty$ & 0 & 250.23 & 72.44 & $\infty$ & $\infty$ & $\infty$ \\
\hline D & $\infty$ & 64.82 & 250.23 & 0 & $\infty$ & 74.93 & $\infty$ & $\infty$ \\
\hline E & $\infty$ & $\infty$ & 72.44 & 74.93 & 0 & 248.07 & 65.60 & $\infty$ \\
\hline F & $\infty$ & $\infty$ & $\infty$ & $\infty$ & 248.07 & 0 & $\infty$ & 79.65 \\
\hline G & $\infty$ & $\infty$ & $\infty$ & $\infty$ & 65.60 & $\infty$ & 0 & 233.39 \\
\hline H & $\infty$ & $\infty$ & $\infty$ & $\infty$ & $\infty$ & 79.65 & 233.39 & 0 \\
\hline
\end{tabular}


3. Menghitung jalur terpendek (d) dengan mengambil posisi awal (A)

- $\operatorname{Jalur}(A, B)$ atau $d(B) \quad=247.87$

- $\operatorname{Jalur}(A, C)$ atau $d(C) \quad=64.82$

- $\operatorname{Jalur}(A, D)$ atau $d(D) \quad=\infty$

- $\operatorname{Jalur}(\mathrm{A}, \mathrm{E})$ atau $\mathrm{d}(\mathrm{E}) \quad=\infty$

- $\operatorname{Jalur}(A, F)$ atau $d(F) \quad=\infty$

- $\operatorname{Jalur}(A, G)$ atau $d(G) \quad=\infty$

- $\operatorname{Jalur}(\mathrm{A}, \mathrm{H})$ atau $\mathrm{d}(\mathrm{H}) \quad=\infty$

Dari perhitungan di atas diperoleh jarak minimum di $(C)$, sehingga jalur yang di dapat yaitu $(A, C)$.

4. Posisi awal (C)

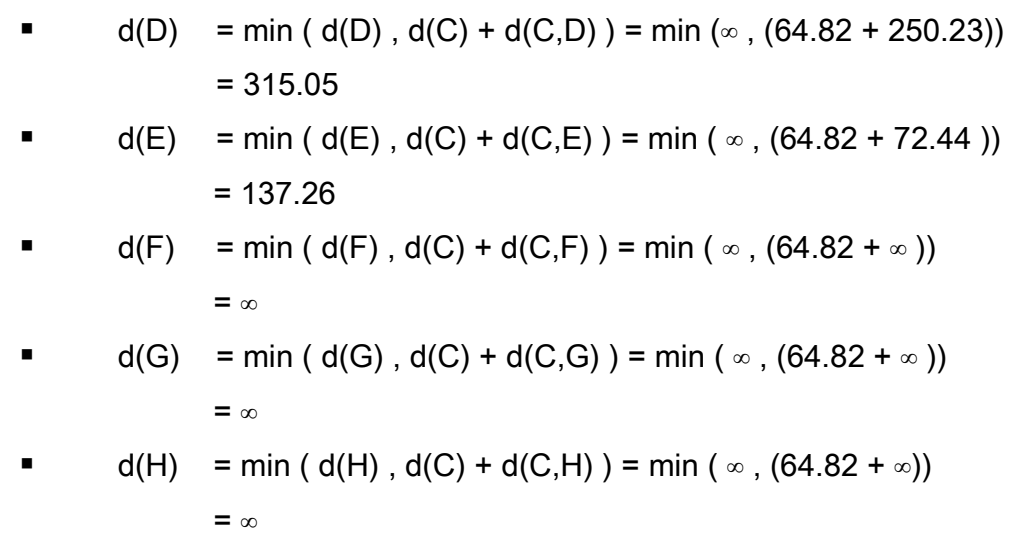

Dari perhitungan di atas diperoleh jarak minimum di (E), sehingga jalur yang di dapat yaitu $(A, C, E)$.

5. Posisi awal (E)

$$
\text { - } \begin{aligned}
\mathrm{d}(\mathrm{F})=\min (\mathrm{d}(\mathrm{F}), \mathrm{d}(\mathrm{E})+\mathrm{d}(\mathrm{E}, \mathrm{F})) & =\min (\infty,(137.26+248.07)) \\
& =385.33 \\
\mathrm{~d}(\mathrm{G})=\min (\mathrm{d}(\mathrm{G}), \mathrm{d}(\mathrm{E})+\mathrm{d}(\mathrm{E}, \mathrm{G})) & =\min (\infty,(137.26+65.60)) \\
& =202.86 \\
\mathrm{~d}(\mathrm{H})=\min (\mathrm{d}(\mathrm{H}), \mathrm{d}(\mathrm{E})+\mathrm{d}(\mathrm{E}, \mathrm{H})) & =\min (\infty,(137.26+\infty)) \\
& =\infty
\end{aligned}
$$

Dari perhitungan di atas diperoleh minimum di $(G)$, sehingga jalur yang didapat yaitu $(A, C, E, G)$ 
6. Posisi awal $(\mathrm{G})$

- $d(H)=\min (d(H), d(G)+d(G, H))=\min (\infty, 202.86+233.39)$

$$
=436.25
$$

Dari perhitungan di atas diperoleh minimum di $(C)$, sehingga jalur yang didapat yaitu $(A, C, E, G, H)$, maka jalur terpendek dari $A$ ke $H$ adalah $(A, C, E, G, H)$ dengan jarak 436.25 meter, ditunjukkan dengan garis merah pada gambar dibawah ini.

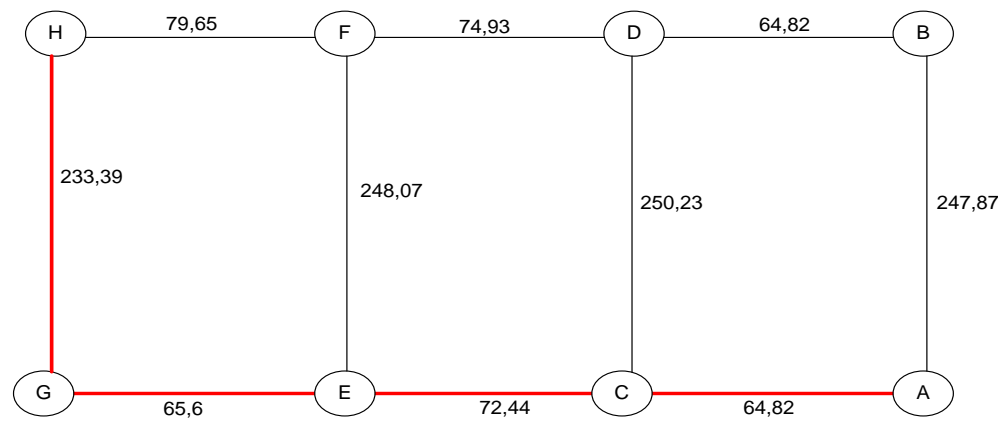

Gambar 3. Graf jalur terpendek dari lokasi user A ke kendaraan bermotor $\mathrm{H}$.

\subsection{Pembahasan}

Desain dan perancangan yang telah dibuat kemudian direalisasikan kedalam aplikasi berikut adalah tampilan dari hasil desain dan perancangan aplikasi berbasis internet.

1. Alur Kerja antara Aplikasi, Server dan Modul

Dalam membuat dan merancang aplikasi anti maling kendaraan bermotor ini dibutuhkan beberapa alat yang disatukan dalam bentuk modul yang akan dipasang pada kendaraan bermotor guna untuk mengidentikasi kendaraan tersebut serta dibutuhkan juga database yang terdapat pada server guna untuk menyimpan semua data-data yang dibutuhkan untuk menjalankan aplikasi. Pada penelitian ini server juga berfungsi sebagai perantara pengiriman data dan perintah antara aplikasi dan modul. Berikut ini adalah alur kerja antara aplikasi, server dan modul. 


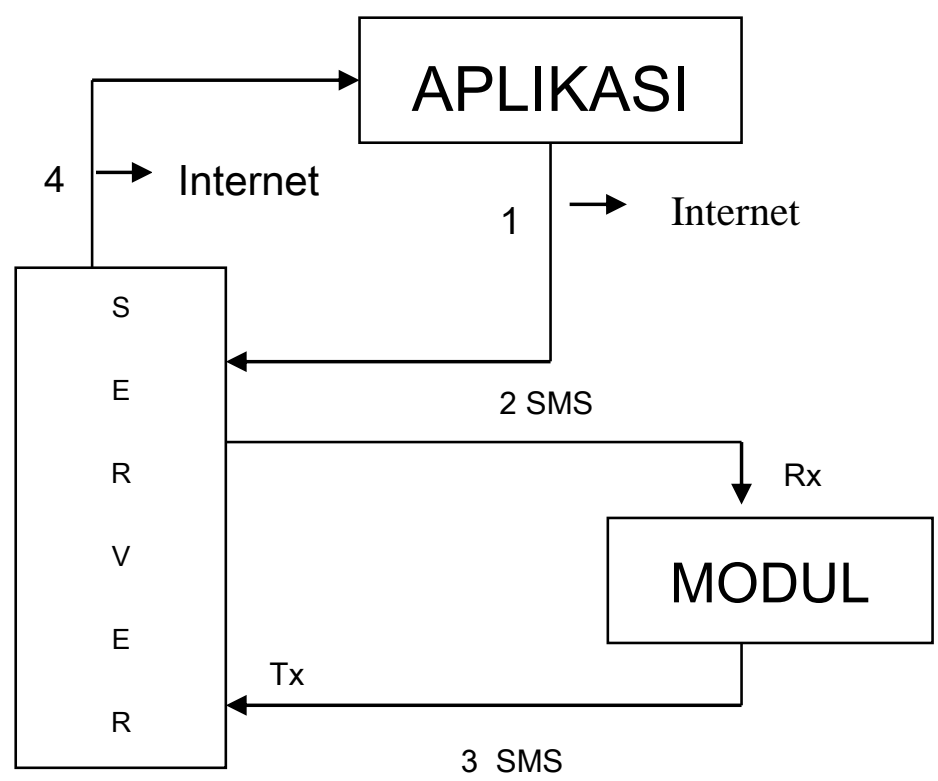

Gambar 4. Alur kerja aplikasi, server dan modul.

Pada gambar diatas ketika salah satu tampilah menu pada aplikasi diklik maka secara otomatis perintah akan dikirimkan ke server dalam bentuk ID melalui internet. Di server ID tersebut akan dicocokkan dengan data ID yang telah disimpan dalam program database setelah itu perintah kemudian diteruskan ke modul melalui sms. Di modul perintah dalam bentuk sms tersebut dicocokkan kembali pada database yang terdapat didalam mikrokontroler dan ketika data yang dikirim cocok maka perintah akan dijalankan, kemudian hasil dari perintah tersebut dikrim kembali ke server dalam bentuk SMS, dan diserver data tersebut disimpan dalam database dan diteruskan ke aplikasi. Pada server dan modul terjadi pengiriman USART yaitu pengiriman data menggunakan 2 kabel data Tx (mengirim) dan Rx (menerima). Tujuan pengiriman secara USART ini adalah agar data yang dikirim tidak saling tabrakan dan amburadul.

\section{Rancangan Aplikasi GPSearch AMK}

Aplikasi GPSearch AMK ini dibuat dengan menggunakan beberapa program dasar yang terdiri dari beberapa menu pada menu utama seperti gambar dibawah ini. Alur kerja program yang dihasilkan dijelaskan dalam gambar 5 . 


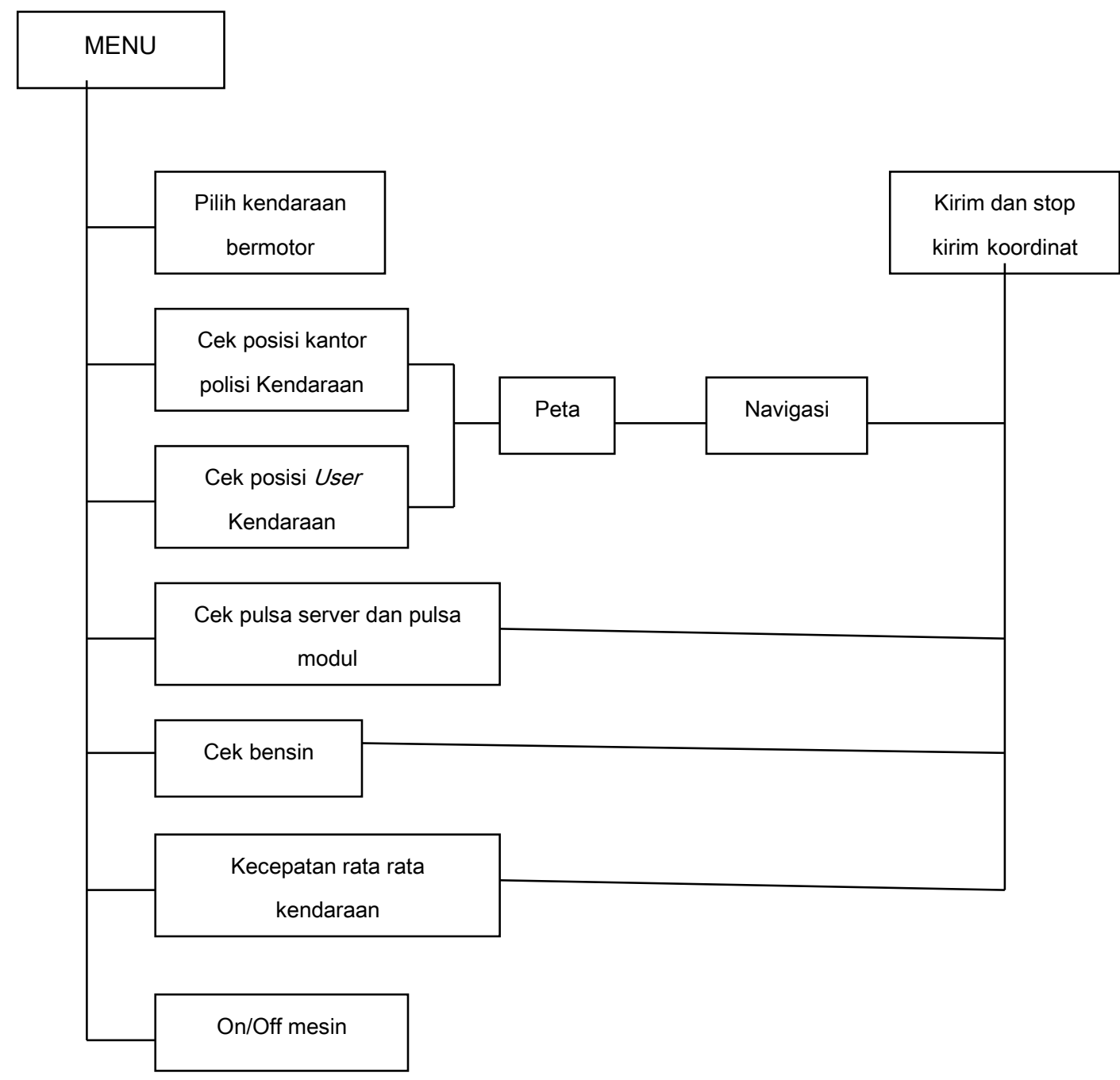

Gambar 5. Struktur pilihan menu GPSearch AMK

Tampilan utama merupakan tampilan list yang memuat beberapa elemen dari aplikasi. Penambahan ikon pada list ini dimaksudkan untuk menjadikan tampilan utama agar menjadi lebih menarik. Tampilan utama GPSearch AMK yaitu tampilan login dapat dilihat pada gambar 6 . 


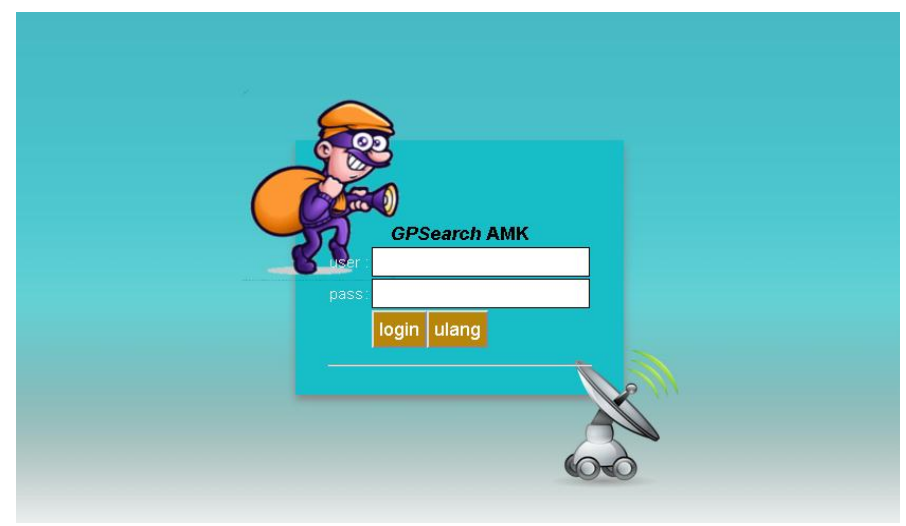

Gambar 6. Tampilan login aplikasi GPSearch AMK

Setelah mengisi ketentuan-ketentuan yang berlaku pada tampilan login, maka akan muncul tampilan aplikasi yang memuat berbagai ikon-ikon menu GPSearch AMK. Berikut contoh tampilannya:

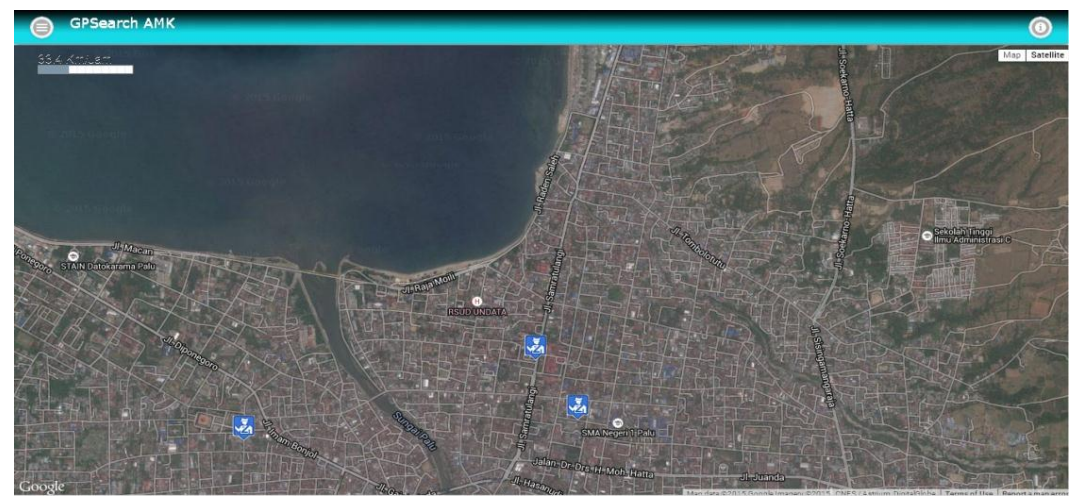

Gambar 7. Tampilan eksekusi menu GPSearch AMK dalam bentuk satelit.

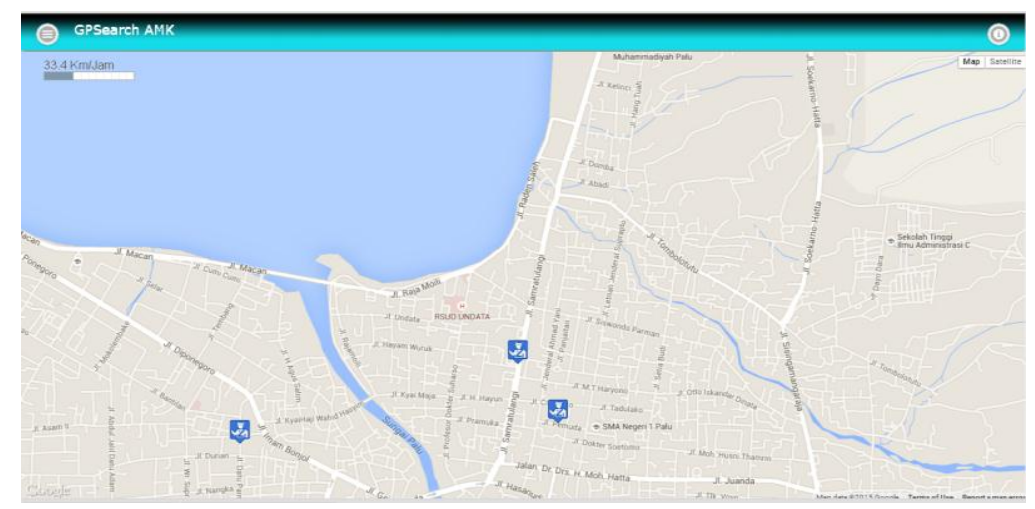

Gambar 8. Tampilan eksekusi menu GPSearch AMK dalam bentuk map 
Pada Gambar 7 dan 8 terdapat beberapa tampilan ikon dimana ikon tersebut mempunyai masing masing fungsi. Pada ikon pojok kiri berfungsi untuk menampilkan tampilan menu serta tampilan on/off mesin dan tampilan bensin kendaraan dan pada ikon pojok kanan merupakan tikon yang berfungsi sebagai navigasi penunjuk arah. Dibawah ikon navigasi terdapat ikon yang bertuliskan Map/Satelit yang berfungsi menampilkan tampilan peta dalam bentuk tampilan peta biasa atau tampilan satelit sesuai dengan keinginan. Ditengah tengah peta yang letaknya ujung atas dekat dengan ikon menu terdapat ikon yang bertuliskan angka yang berfungsi untuk menampilkan tampilan kecepatan rata-rata kendaraan bermotor. Berikut tampilan menu-menu yang berada pada ikon pojok kiri ketika ikon tersebut diklik.

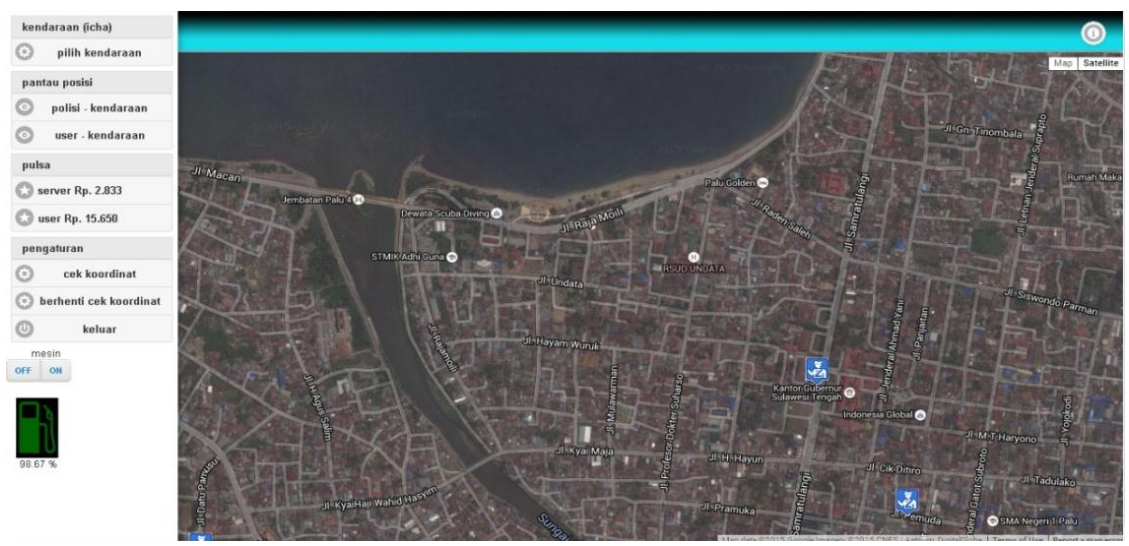

Gambar 9. Tampilan eksekusi menu GPSearch AMK

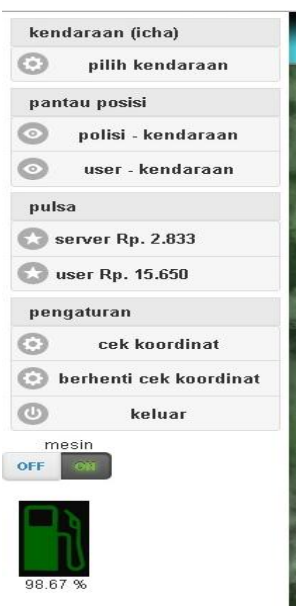

Gambar 10. Tampilan eksekusi menu GPSearch AMK (diperbesar) 


\section{Kesimpulan}

Berdasarkan hasil penelitian yang telah dilakukan, maka disimpulkan bahwa:

1. Untuk masuk kedalam aplikasi anti maling kendaraan bermotor atau GPSearch AMK digunakan alamat website dan untuk membuka login dari aplikasi GPSearch AMK digunakan nama Userdan password.

2. Telah dihasilkan aplikasi anti maling pada kendaraan bermotor menggunakan GPS berbasis internet.

3. Aplikasi anti maling kendaraan bermotor menggunakan GPS berbasis internet atau disebut GPSearch AMK ini dapat digunakan untuk memantau dan mengontrol kendaraan ketika kendaraan bermotor tersebut dicuri atau hilang. Pemantauan atau pengontrolan tersebut berupa:

- Memilih kendaraan bermotor yang akan dipantau.

- Memantau posisi antara kantor polisi dengan kendaraan bermotor.

- Mengecek jalur terpendek antara User dengan kendaraan bermotor.

- $\quad$ Menampilkan tampilan jumlah pulsa pada handphone di server dan jumlah pulsa pada handphone dimodul.

- Mengatur pengiriman koordinat GPS.

- Menampilkan tampilan jumlah bensin pada kendaraan bermotor.

- Menampilkan tampilan on/off mesin kendaraan bermotor.

- Menampilkan tampilan navigasi penunjuk arah.

- Menampilkan tampilan peta.

4. Aplikasi ini akan bekerja dengan baik jika tersedia jaringan $3 G / 4 G$ dan pulsa.

\section{DAFTAR PUSTAKA}

[1]. Amry, M.S., 2011, Membangun Sistem Navigasi Di Surabaya Menggunakan Google Maps $A P I$, Institut Teknologi Sepuluh November Surabaya, Surabaya.

[2]. Handojo, A., Lim, R., dan Hendrawati, F., 2004, Aplikasi Pelacakan Lokasi Rute Perjalanan Mobil dengan GPS Via SMS, (http://fportfolio.petra.ac.id/user_files/00-016/SemNas\% 20UTY\%20GPS-car\%20security\%20rute\%20Andreas\%20H.pdf, diakses 18 September 2014).

[3]. Lim, R., Sandjaja, I, N., dan Yulimingtarto, J., 2003, Pengolahan Data GPS Yang Dikirim Dengan Tekhnologi SMS Untuk Pelacakan Kendaraan, Kajian Jurnal Penelitian, Universitas Kristen Petra, (http://web.iaincirebon.ac.id, diakses 15 Juni 2014). 
[4]. Lubis, H.S., 2009, PerbandinganAlgoritma Greedy Dan Dijkstra Untuk Menentukan Lintasan Terpendek, Usu Repository (C) 2009, (http://repository.usu.ac.id, diakses 18 September 2014).

[5]. Tjhin, S., Amami, M., Ahmad, M. T., dan Faqih, A., 2014, Sistem Keamanan Sepeda Motor Melalui Short Message Service Menggunakan AVR Mikrokontroler Atmega8, Universitas Surya, Tangerang, Banten.

[6]. Zaif, A., 2013, Program Bahasa Assembly (Assembler), (Online), (http://zaifbio.wordpress.com/2013/01/02/pemrograman-bahasa-assembly-assembler/, diakses 12 Oktober 2014). 